\title{
Crop Discrimination using Non-Imaging Hyperspectral Data
}

\author{
Pooja Vinod Janse, Ratnadeep R. Deshmukh
}

\begin{abstract}
Crop type discrimination is still very challenging task for researchers using non-imaging hyperspectral data. It is because of spectral reflectance similarity between crops. In this research work we have discriminated between four crops wheat, jowar, bajara and maize. We have tried to overcome the problems which have been faced my researchers. Initially by visual analysis we have selected 22 reflectance band which shows the absorption property of particular molecules and classification techniqueis applied, but it has given us very poor result of classification. We observed only $24 \%$ classification accuracy. So we considered nine vegetation indices along with spectral bands and achieved better classification accuracy. ASD FieldSpec 4 Spectroradiometer device is used for capturing spectral reflectance data. We calculated nine different vegetation indices and some selective reflectance bands are used for crop classification. We have used Support Vector Machine (SVM) for classification.
\end{abstract}

Keywords: Crop Discrimination, ASD FieldSpec 4 Spectroradiometer, Support Vector Machine, Vegetation Indices

\section{INTRODUCTION}

$\mathrm{R}$ Remote sensing is being increasingly used in different agricultural applications. Hyper spectral remote sensing in large continuous narrow wavebands provides significant advancement in understanding the subtle changes in biochemical and biophysical attributes of the crop plants and their different physiological processes, which otherwise are indistinct in multispectral remote sensing [1].

Hyper spectral remote sensing has been applied to many agriculture applications such as crop stress and diseases, however, the potential use of this technique for disease detection under field conditions is unknown. Hyper spectral remote sensing, also known as imaging and nonimagingspectroscopy is useful for various applications such as the detection and identification of minerals from crops, terrestrial vegetation, and man-made materials [2].

Manuscript received on June 10, 2021.

Revised Manuscript received on June 14, 2021.

Manuscript published on June 30, 2021.

* Correspondence Author

Pooja Vinod Janse*, Department of Computer Science and IT, Dr. Babasaheb Ambedkar Marathwada University, Aurangabad(Maharashtra), India. Email: puja.janse@hotmail.com

Ratnadeep R. Deshmukh, Department of Computer Science and IT, Dr. Babasaheb Ambedkar Marathwada University, Aurangabad(Maharashtra), India.Email: rrdeshmukh.csit@bamu.ac.in

(C) The Authors. Published by Blue Eyes Intelligence Engineering and Sciences Publication (BEIESP). This is an open access article under the CC BY-NC-ND license (http://creativecommons.org/licenses/by-nc-nd/4.0/)

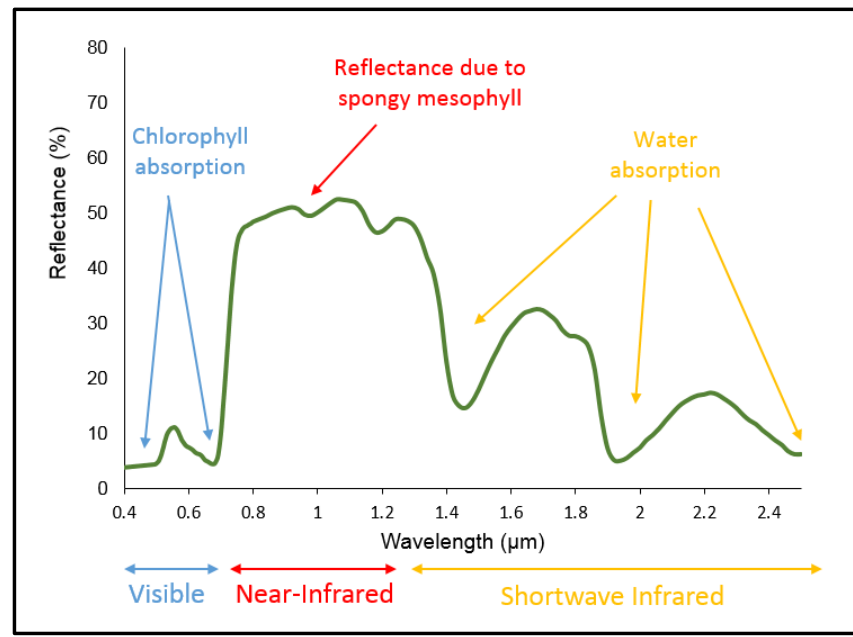

Fig. 1: Spectral Signature of Vegetation

Here in figure 1 we can see spectral signature of vegetation. The general reflectance shape and transmission curves for green vegetation is similar for all types of crop species. It is featured by absorption of specific molecules and the cellular arrangement of the leaf tissue. In the visible region (400-700nm), chlorophyll a and b (Chl a and b), xanthophyll, carotenoids and polyphenols shows absorption. Chl a shows maximum absorption in 410-430nm and 600$690 \mathrm{~nm}$ region. Chl b shows absorption in 450-470nm.

In near-infrared (NIR-700-1300nm) region cellulose and other leaf pigments are transparent in nature so they shows very low absorption and higher reflectance and transmittance value.

In shortwave infrared (SWIR-1300-2500nm) region, water and other foliar constituents affects leaf optical properties. The major absorption bands of water are $1450 \mathrm{~nm}$ and $1940 \mathrm{~nm}$.

We have used these spectral reflectance properties and some vegetation indices for crop classification purpose which given us satisfactory result.

\section{MATERIAL AND METHODS}

\section{A. Study Area}

Leaf samples of Bajara, Cotton, Jowar, Maize and Wheat from Paithan Road, Chikalthana and Harsool road Area of Aurangabad region were collected. The latitude value of Aurangabad, Maharashtra is $19.8762^{\circ} \mathrm{N}$ and longitude value is $75.3433^{\circ} \mathrm{E}$. The mentioned study area is consist of both man made material and agricultural fields.
Blue Eyes Intelligence Engineering and Sciences Publication

(C) Copyright: All rights reserved.

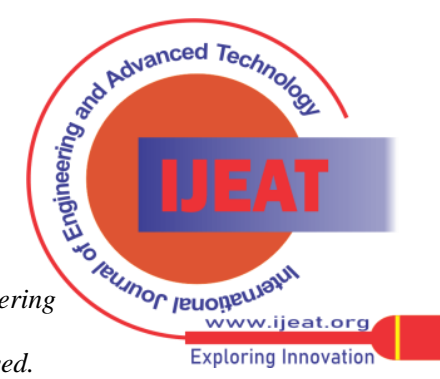




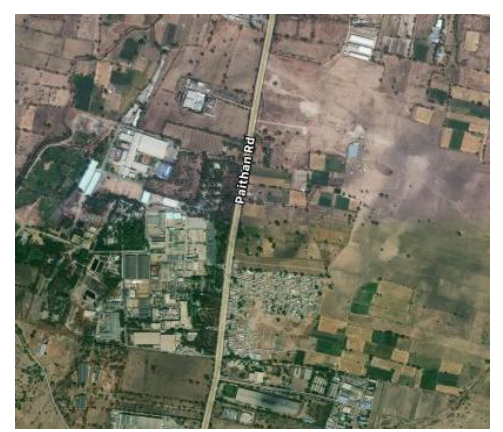

(a)

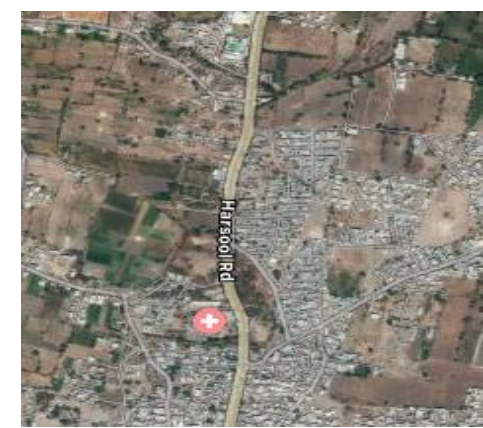

(b)

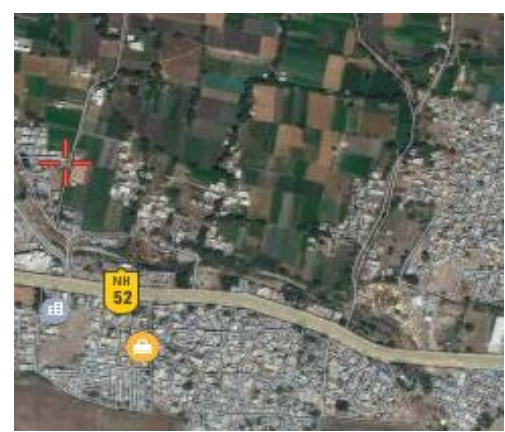

(c)

Fig. 2: Satellite image of the study area (a) Paithan road, (b) Harsool road, and (c) Chikalthana

\section{B. Leaf Sample Preparation and Laboratory Setup}

Leaf samples of Bajara, Cotton, Jowar, Maize and Wheat were cut from plant and immediately kept in air tight plastic bag so that there will be no or very less loss of its biological properties. These samples then brought to laboratory in Department of Computer Science and IT, Dr. Babasaheb Ambedkar Marathwada University, Aurangabad, Maharashtra for spectral signature generation.

We have collected spectral signature of leaf samples by using ASD FieldSpec4 spectroradiometer and RS3 software. We collected database in laboratory in controlled condition, it was a dark room specially created for spectral data collection because other colors and light sources will affect the spectral signature. The spectrometer setup is shown in figure 3 .

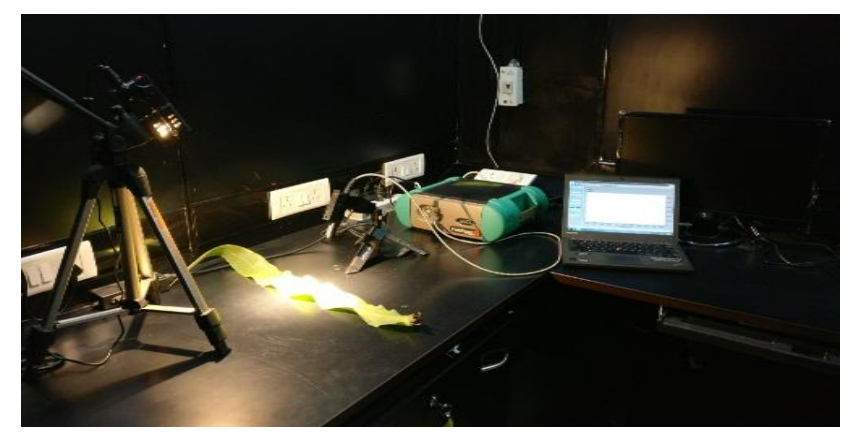

Fig. 3: Spectrometer Setup in data collection process

\section{Instrumentation and Software}

Analytical Spectral Device (ASD) FieldSpec 4 Spectroradiometer is a primary tool used for generating hyperspectral signature data. It is general-purpose instrument which has proven effectiveness of application in several areas which require measurement of reflectance, transmittance, radiance, or irradiance. FieldSpec 4 Spectroradiometer is a compact and field portable device of incredible precision, with a spectral range of $350 \mathrm{~nm}$ to 2500 $\mathrm{nm}$.

RS3, ViewSpec Pro, Microsoft Excel are essential software's which are used in this study. RS3 software states to the version of the Analytical Spectral Devices application. Its purpose is to receive and store the spectral signature data transmitted from ASD Spectroradiometer. ViewSpec pro software is used for converting .asd file into ASCII file of .txt format. ENVI is useful for analysis, visualization and presentation of data.

We have warmed up ASD Fieldspec4 Spectroradiometer for 30 minutes before data collection. Distance between spectral gun and light source was kept $50 \mathrm{~cm}$. Distance between spectral gun and sample was set to $8 \mathrm{~cm}$. and
80Field of View (FOV) was used. Then we used RS3 Software for capturing spectral signature. The splash screen of RS3 is shown in figure 4.

Then Spectroradiometer have been optimized first to set the appropriate light source settings. Then white reference panel reading have been measured. Then spectral signature of leaf samples have been collected. Leaf spectral measurement provides reflectance values from 350nm2500nm.

\section{Spectral Data Processing for analysis}

The spectral data which is captured using ASD Spectroradiometer were received and stored using RS3 software in .asd format. The spectral data then be viewed with ViewSpec Pro after necessary conversion from .asd format to ASCII in .txt format. The ViewSpec Pro software was used for the data conversion process. All the spectral data saved in .asd format were transferred to ASCII and later saved as .txt format. Furthermore, the data arrangement process was carried out using Microsoft Excel to average all the spectra data obtained from ASD Spectroradiometer device $[3,4,5]$.

The reflectance band showing absorption characteristics of particular molecule are taken into consideration for statistical analysis. Table I shows spectral band and its absorption properties.

Table-I: Vegetative characteristics and their centered spectral band[2]

\begin{tabular}{|c|c|}
\hline Reflectance Band & Vegetative Characteristics \\
\hline 370 & Phototropism \\
\hline 420 & a - Carotene \\
\hline 425 & b - Carotene \\
\hline 430 & Chlorophyll a \\
\hline 440 & a - Carotene \\
\hline 445 & b - Carotene \\
\hline 450 & Chlorophyll b \\
\hline 453 & a - Carotene \\
\hline 470 & Xanthophyll \\
\hline 475 & b - Carotene \\
\hline 480 & Synthesis of Chlorophyll \\
\hline 650 & Chlorophyll absorption \\
\hline 960 & Chlorophyll absorption \\
\hline 1100 & Water absorption \\
\hline 1400 & Water absorption \\
\hline 1930 & Peak Al - OH, Mg - OH, $\mathrm{CO}_{3}$ \\
\hline 2200 &
\end{tabular}

Published By:

Blue Eyes Intelligence Engineering and Sciences Publication

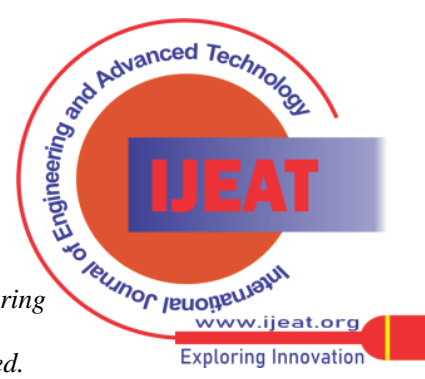




\section{E. Vegetation indices}

Vegetation indices are used as potential variables for crop type discrimination. Some of those are used in this research work for getting more clear result of classification. Table II shows vegetation indices used in crop discrimination process.

Table-II: Vegetation indices calculated from hyperspectral data[2]

\begin{tabular}{|c|c|c|c|}
\hline $\begin{array}{l}\text { Sr. } \\
\text { No. }\end{array}$ & $\begin{array}{l}\text { Vegetatio } \\
\text { n Indices }\end{array}$ & Equation & Use \\
\hline 1 & $\begin{array}{l}\text { Lipidium } \\
\text { Index (LI) }\end{array}$ & $\mathrm{R}_{630} / \mathrm{R}_{586}$ & $\begin{array}{l}\text { Sensitive to bright } \\
\text { reflectance displayed } \\
\text { by Lipidium in } \\
\text { visible range }\end{array}$ \\
\hline 2 & $\begin{array}{c}\text { Normalize } \\
\text { d } \\
\text { Difference } \\
\text { Vegetatio } \\
\text { n Index } \\
\text { (NDVI) }\end{array}$ & $\begin{array}{c}\left(\mathrm{R}_{864}-\mathrm{R}_{671}\right) /\left(\mathrm{R}_{864}\right. \\
\left.+\mathrm{R}_{671}\right)\end{array}$ & $\begin{array}{l}\text { Respond to change in } \\
\text { amount of green } \\
\text { biomass and more } \\
\text { efficiently in } \\
\text { vegetation }\end{array}$ \\
\hline 3 & $\begin{array}{l}\text { Simple } \\
\text { Ratio } \\
\text { (SR) }\end{array}$ & $\mathrm{R}_{864} / \mathrm{R}_{671}$ & Same as NDVI \\
\hline 4 & $\begin{array}{c}\text { Pigment } \\
\text { Specific } \\
\text { Normalize } \\
\text { d } \\
\text { Difference } \\
\text { (PSND) }\end{array}$ & $\begin{array}{c}\left(\mathrm{R}_{800}-\mathrm{R}_{470}\right) /\left(\mathrm{R}_{800}\right. \\
\left.+\mathrm{R}_{470}\right)\end{array}$ & $\begin{array}{l}\text { Estimates LAI and } \\
\text { Carotenoids }\end{array}$ \\
\hline 5 & (RVI) & $\mathrm{R}_{1088} / \mathrm{R}_{1148}$ & $\begin{array}{c}\text { Quantify LAI and } \\
\text { water content at } \\
\text { canopy Level }\end{array}$ \\
\hline 6 & $\begin{array}{l}\text { Water } \\
\text { Index } \\
(\mathrm{WI}) \\
\end{array}$ & $\mathrm{R}_{900} / \mathrm{R}_{970}$ & $\begin{array}{c}\text { Quantify relative } \\
\text { water content at leaf } \\
\text { level }\end{array}$ \\
\hline 7 & $\begin{array}{l}\text { SGI (Sum } \\
\text { Green } \\
\text { Index) }\end{array}$ & $\begin{array}{c}\left(\mathrm{R}_{508}+\mathrm{R}_{518}\right. \\
+\mathrm{R}_{528}+\mathrm{R}_{538}+\mathrm{R}_{549}+ \\
\mathrm{R}_{559}+\mathrm{R}_{569}+\mathrm{R}_{579}+\mathrm{R}_{5} \\
\left.90+\mathrm{R}_{600}\right) / 10\end{array}$ & \\
\hline 8 & $\begin{array}{c}\text { Red Edge } \\
\text { NDVI }\end{array}$ & $\begin{array}{c}\left(\mathrm{R}_{752}-\mathrm{R}_{701}\right) /\left(\mathrm{R}_{752}\right. \\
\left.+\mathrm{R}_{701}\right)\end{array}$ & \\
\hline
\end{tabular}

\begin{tabular}{|c|c|l|l|}
\hline & (RENDVI & & \\
\hline & ) & & \\
9 & $\begin{array}{c}\text { Vogelman } \\
\text { n Red }\end{array}$ & & \\
& Edge & $\mathrm{R}_{742} / \mathrm{R}_{722}$ & \\
& $\begin{array}{c}\text { Index- I } \\
\text { (VOG-I) }\end{array}$ & & \\
\hline
\end{tabular}

\section{METHODOLOGY}

For crop type classification support vector machine (SVM) [6,7] classifier is used which has given satisfactory results. Steps of SVM is as follows.

- Import the dataset

- Pre-process the data

- Split the data into attributes and labels

- Divide the data into training and testing sets

- Train the SVM algorithm

- Make some predictions

- Evaluate the results of the algorithm

SVMs is dissimilar than other algorithms of classification because of the way they choosing the decision boundary that exploits the distance from the nearest data points of all the classes.

\section{RESULT AND DISCUSSION}

By making visual analysis we identified and analyzed difference between spectral signatures of four crops wheat, Jowar, Bajara and Maize. This severability is verified by SVM classification algorithm. We prepared dataset using vegetation indices. Some of the samples vegetation indices are listed in table III.

We have also taken reflectance value into consideration where particular molecule shows its reflectance property. Some of those sample values are also listed in table IV.

Table-III: Vegetation Indices performed on Wheat, Bajara, Jowar and Maize leaf spectral signature

\begin{tabular}{|c|c|c|c|c|c|c|c|c|c|}
\hline LI & NDVI & SR & PSND & RVI & WI & RENDVI & VOG & SGI & CLASS \\
\hline 0.8532 & 0.5991 & 3.9898 & 0.604 & 1.0518 & 1.0233 & 0.381 & 1.2222 & 0.1565 & Bajara \\
\hline 0.849 & 0.6782 & 5.2155 & 0.6593 & 1.0524 & 1.0308 & 0.5332 & 1.4293 & 0.1732 & Bajara \\
\hline 0.8729 & 0.5866 & 3.8384 & 0.5741 & 1.0598 & 1.0353 & 0.41 & 1.2975 & 0.1933 & Bajara \\
\hline 0.8926 & 0.5249 & 3.2096 & 0.525 & 1.0398 & 1.0153 & 0.3333 & 1.2602 & 0.1813 & Jowar \\
\hline 0.8784 & 0.4527 & 2.6546 & 0.426 & 1.0515 & 1.0255 & 0.2627 & 1.1499 & 0.457 & Jowar \\
\hline 0.7475 & 0.8226 & 10.28 & 0.8243 & 1.0551 & 1.028 & 0.5863 & 1.4647 & 0.1085 & Maize \\
\hline 0.7731 & 0.6592 & 4.8702 & 0.6546 & 1.05 & 1.0308 & 0.3958 & 1.1901 & 0.2605 & Maize \\
\hline 0.8358 & 0.7188 & 6.1136 & 0.7434 & 1.0798 & 1.0344 & 0.4782 & 1.3444 & 0.0707 & Wheat \\
\hline 0.8539 & 0.7692 & 7.6666 & 0.7344 & 1.0481 & 1.0232 & 0.6248 & 1.5222 & 0.1 & Wheat \\
\hline
\end{tabular}

Table -IV:Reflectance values of Wheat, Bajara,Jowar and Maize leaf spectral signature at specific band

\begin{tabular}{|c|c|c|c|c|c|c|c|c|c|c|c|c|c|c|c|c|c|}
\hline $\mathbf{3 7 0}$ & $\mathbf{4 2 0}$ & $\mathbf{4 2 5}$ & $\mathbf{4 3 0}$ & $\mathbf{4 4 0}$ & $\mathbf{4 4 5}$ & $\mathbf{4 5 0}$ & $\mathbf{4 5 3}$ & $\mathbf{4 7 0}$ & $\mathbf{4 7 5}$ & $\mathbf{4 8 0}$ & $\mathbf{6 5 0}$ & $\mathbf{9 6 0}$ & $\mathbf{1 1 0 0}$ & $\mathbf{1 4 0 0}$ & $\mathbf{1 9 3 0}$ & $\mathbf{2 2 0 0}$ & $\mathbf{C L A S S}$ \\
\hline 0.074 & 0.081 & 0.084 & 0.086 & 0.089 & 0.091 & 0.093 & 0.094 & 0.097 & 0.097 & 0.098 & 0.114 & 0.387 & 0.406 & 0.209 & 0.079 & 0.205 & Bajara \\
\hline 0.114 & 0.112 & 0.115 & 0.117 & 0.119 & 0.121 & 0.122 & 0.123 & 0.124 & 0.124 & 0.124 & 0.125 & 0.586 & 0.601 & 0.303 & 0.116 & 0.273 & Bajara \\
\hline 0.107 & 0.113 & 0.118 & 0.121 & 0.126 & 0.129 & 0.131 & 0.133 & 0.135 & 0.135 & 0.136 & 0.144 & 0.483 & 0.495 & 0.258 & 0.097 & 0.222 & Bajara \\
\hline 0.087 & 0.101 & 0.104 & 0.107 & 0.111 & 0.114 & 0.117 & 0.119 & 0.123 & 0.125 & 0.126 & 0.148 & 0.393 & 0.391 & 0.235 & 0.084 & 0.198 & Jowar \\
\hline
\end{tabular}

Published By:

Blue Eyes Intelligence Engineering and Sciences Publication

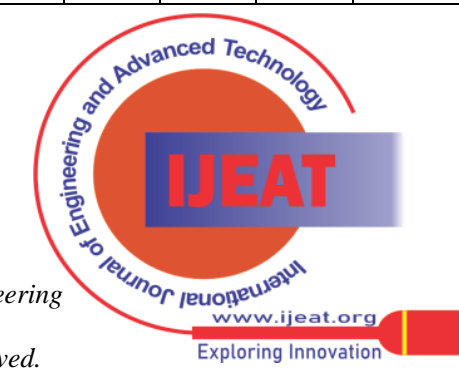




\begin{tabular}{|c|c|c|c|c|c|c|c|c|c|c|c|c|c|c|c|c|c|}
\hline 0.217 & 0.284 & 0.293 & 0.3 & 0.307 & 0.313 & 0.318 & 0.321 & 0.326 & 0.326 & 0.328 & 0.346 & 0.786 & 0.773 & 0.451 & 0.184 & 0.359 & Jowar \\
\hline 0.038 & 0.043 & 0.044 & 0.046 & 0.046 & 0.047 & 0.048 & 0.048 & 0.049 & 0.049 & 0.049 & 0.065 & 0.502 & 0.517 & 0.229 & 0.048 & 0.205 & Maize \\
\hline 0.138 & 0.127 & 0.128 & 0.129 & 0.129 & 0.13 & 0.132 & 0.133 & 0.134 & 0.135 & 0.135 & 0.158 & 0.618 & 0.628 & 0.313 & 0.104 & 0.274 & Maize \\
\hline 0.033 & 0.034 & 0.035 & 0.036 & 0.037 & 0.037 & 0.038 & 0.038 & 0.039 & 0.04 & 0.04 & 0.049 & 0.262 & 0.283 & 0.115 & 0.022 & 0.099 & Wheat \\
\hline 0.058 & 0.07 & 0.074 & 0.077 & 0.08 & 0.081 & 0.082 & 0.082 & 0.081 & 0.081 & 0.08 & 0.071 & 0.517 & 0.521 & 0.254 & 0.046 & 0.202 & Wheat \\
\hline
\end{tabular}

From the above table we can see preprocess data taken for classification purpose. We have collected total 145 leaf samples and tenspectral signature of each leaf have been recorded. Mean of ten spectral signature of each leaf calculated and mean spectral signature id considered for classification. Vegetation indices are also calculated on mean spectral signature. As spectral data of leaf was recorded in controlled condition and in dark room, environmental factors like clouds, humidity, temperature, wind speed and direction, cloud cover, smoke and haze does not effects on spectral data collected.

We have defined dependent and independent variables first and divided data into training and testing samples. We used $80 \%$ data for training and rest $20 \%$ data for testing.
We built SVM classifier model on data and provided some prediction.

SVM classifier provided $100 \%$ result of classification.

Confusion matrix is as shown below.

Confusion Matrix $=\quad\left[\left[\begin{array}{llll}30 & 0 & 0 & 0\end{array}\right]\right.$

$$
\begin{aligned}
& {\left[\begin{array}{rrrr}
0 & 40 & 0 & 0
\end{array}\right]} \\
& {\left[\begin{array}{llll}
0 & 0 & 40 & 0
\end{array}\right]} \\
& {\left[\begin{array}{llll}
0 & 0 & 0 & 35
\end{array}\right]}
\end{aligned}
$$

Above confusion matrix shows that 30 sample of Bajara, 40 samples of Jowar and Maize, 35 samples of Wheat are correctly classified. Precision, recall and f1-score values are shown in table- $V$. It means that all samples are correctly classified and 100\% accuracy achieved by SVM algorithm.

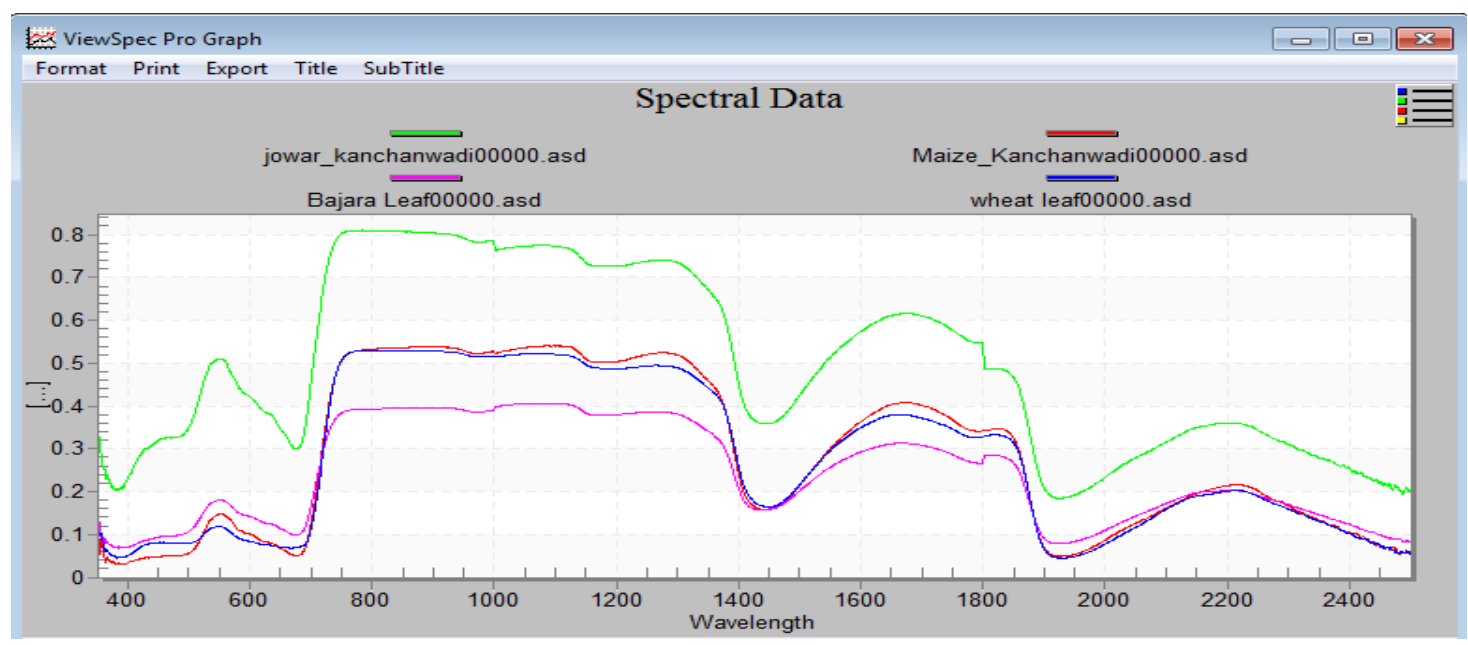

Fig. 4: Spectral Signature of Wheat, Bajara, Jowar and Maize leaf

Table-V: Precision, recall and f1-score values

\begin{tabular}{|c|c|c|c|}
\hline & Precision & Recall & F1-Score \\
\hline Bajara & 1 & 1 & 1 \\
\hline Jowar & 1 & 1 & 1 \\
\hline Maize & 1 & 1 & 1 \\
\hline Wheat & 1 & 1 & 1 \\
\hline
\end{tabular}

\section{CONCLUSION}

Spectral signature analysis of four crops shows their characterization based on reflectance on particular band. Initially we considered only reflectance values for classification using SVM but it has given very poor result. As we seen spectral reflectance of four crops that shows reflectance value of maize and wheat are nearly similar. So we decided to consider some more features like vegetation indices for classification which has given 100\% classification result. It has also been observed that NDVI, RVI, SR and RENDVI vegetation indices plays very important role in classification. Also red-edge position in spectral signature is also feasible spectral region for crop classification. In this research work we have used SVM for classification but many other methods like Principle Component Analysis (PCA), Linear Discriminant Analysis (LDA), and PLSR Regression can also be used for getting better result. 


\section{ACKNOWLEDGMENT}

Authors would like to thank DST-FIST project for providing support for this research work. Author also extends heartfelt thanks to Computer Science and IT department, Dr. Babasaheb Ambedkar Marathwada University, Aurangabad, Maharashtra for providing Lab setup for data collection.

\section{REFERENCES}

1. Pooja Vinod Janse, Ratnadeep R. Deshmukh, "Hyperspectral Remote Sensing for Agriculture: A Review", IJCA, Vol.-172, No.-7, 2017.

2. Thenkabail, P. S., Smith, R. B. and Pauw, E. D., Hyperspectral vegetation indices and their relationships with agricultural crop characteristics. Remote Sensing Environment, 71:158-182, 2000.

3. Prasad S. Thenkabail, Isabella Mariotto, Murali Krishna Gumma, Elizabeth M. Middleton, David R. Landis, and K. 3. Fred Huemmrich, "Selection of Hyperspectral Narrowbands (HNBs) and Composition of Hyperspectral Two band Vegetation Indices (HVIs) for Biophysical Characterization and Discrimination of Crop Types Using Field Reflectance and Hyperion/EO-1 Data”, IEEE JOURNAL OF SELECTED TOPICS IN APPLIED EARTH OBSERVATIONS AND REMOTE SENSING, VOL. 6, NO. 2, APRIL 2013.

4. Carlos Antonio da Silva Junior, Marcos Rafael Nanni , Muhammad Shakir , Paulo Eduardo Teodoro , José Francisco de Oliveira-Júnior Everson Cezar , Givanildo de Gois , Mendelson Lima , Julio Cesar Wojciechowski, Luciano ShozoShiratsuchi, "Soybean varieties discrimination using non-imaging hyperspectral sensor", Elsevier, Infrared Physics \& Technology 89, 338-350, 2018.

5. Jan Rudolf Karl Lehmann, André Große-Stoltenberg, MeikeRömer and Jens Oldeland, "Field Spectroscopy in the VNIR-SWIR Region to Discriminate between Mediterranean Native Plants and ExoticInvasive Shrubs Based on Leaf Tannin Content", Remote Sens., 7, 1225-1241, 2015.

6. ShreedeviMoharana , Subashisa Dutta, "Hyperspectral Remote Sensing Of Paddy Crop Using In-Situ Measurement And Clustering Technique", The International Archives of the Photogrammetry, Remote Sensing and Spatial Information Sciences, Volume XL-8, 2014.

7. Jeffrey H. Wilson, Chunhua Zhang and John M. Kovacs, "Separating Crop Species in Northeastern Ontario Using Hyperspectral Data", Remote Sens., 6, 925-945, 2014.

\section{AUTHORS PROFILE}

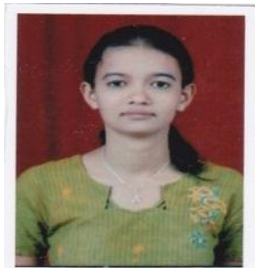

Miss. Pooja V. Janse, is currently pursuing the Ph.D. degree in Computer Science and Engineering from Department of Computer Science and IT, Dr. Babasaheb Ambedkar Marathwada University, Aurangabad, and Maharashtra, India. She is currently working as BSR Senior Research Fellow sanctioned by UGC to the Computer Science and Information Technology Department, Dr. B.A.M. University, Aurangabad. She is a life member of CSI, ISCA, CSTA and IAEng. She has published more than 23 research papers in reputed National and International Journals / conferences. Her research interest includes the digital speech signal processing, Remote Sensing and Geographical Information System (GIS) Technology.

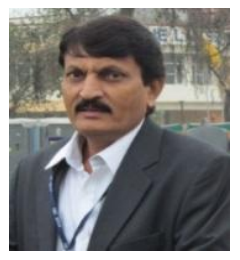

Dr. R. R. Deshmukh, Professor, M.E., M.Sc. (CSE) Ph.D. FIETE, Presently working as Professor in Department of CS \& IT, Dr. B.A.M. University, Aurangabad, (MS), India. He is a Fellow member and working as Chairman, IETE Aurangabad Centre, He has been elected as sectional member of ICT section of Indian Science congress Association. He is life member of ISCA, CSI, ISTE, IEEE, IAEng, CSTA, IDES and a senior member of ACEEE. He was Vice-Chairman of IETE Aurangabad Centre for last 4 years and member of Management Council of Dr. B.A.M. University. He is Member of Academic Council and Senate member of Dr. B.A.M. University, Aurangabad. He published more than 170 research papers in reputed National and International Journals / conferences. He is reviewer and editor of several journals at national \& international level. His areas of specialization are Human Computer Interaction, Digital Speech Signal processing, Data Mining, Data Warehousing, Image Processing, Pattern Recognition, Artificial
Intelligence, Computational Auditory Scene Analysis (CASA), Neural Networks etc. 